\title{
Article
}

Arq Neuropsiquiatr 2010;68(2):228-230

\section{Translation and validation into Brazilian version of the Scale of the Assessment and Rating of Ataxia (SARA)}

\author{
Pedro Braga-Neto ${ }^{1}$, Clecio Godeiro-Junior' , Lívia Almeida Dutra', \\ José Luiz Pedroso', Orlando Graziani Povoas Barsottini²
}

\begin{abstract}
The hereditary ataxias comprise a very large spectrum of genetically determined neurodegenerative disorders with progressive ataxia as the prominent symptom. In order to measure the severity of cerebellar ataxia in an easier and more practical way, it was proposed a new scale: the Scale for the Assessment and Rating of Ataxia (SARA). The objective of this study was to translate and validate SARA into Brazilian Portuguese. Method: The SARA was translated into Brazilian Portuguese, analyzed, back translated to English, and compared to the original version. It was applied to 30 patients. In addition to SARA, we applied the International Cooperative Ataxia Rating Scale (ICARS) in all subjects. Results: SARA scale was translated into Brazilian version with adequate internal consistence, but a significant correlation between ICARS and SARA was not found. Conclusion: SARA was translated and validated into Brazilian Portuguese language, showing good reliability and validity. Key words: cerebellar ataxia, international cooperative ataxia rating scale, scale for the assessment and rating of ataxia.
\end{abstract}

Tradução e validação da escala para avaliação e graduação de ataxia (SARA) para versão brasileira

\section{RESUMO}

As ataxias hereditárias compreendem grande espectro de doenças neurodegenerativas geneticamente determinadas, tendo como sintoma preponderante a ataxia de instalação progressiva. No sentido de avaliar a gravidade da ataxia cerebelar através de forma mais fácil e prática, foi proposta uma nova escala: a Escala para Avaliação e Graduação de Ataxia (SARA). O objetivo deste estudo foi traduzir e validar a SARA para o português brasileiro. Método: A escala SARA foi traduzida para o português brasileiro, analisada, traduzida novamente para o inglês e comparada com sua versão original. A escala foi aplicada em 30 pacientes. Além disso, nós aplicamos também a Escala Cooperativa Internacional para Graduação de Ataxia (ICARS) em todos os pacientes. Resultados: A escala SARA foi traduzida para a versão brasileira com adequada consistência interna, mas uma correlação significativa com a escala ICARS não foi encontrada. Conclusão: A escala SARA foi traduzida e validada para o português brasileiro, demonstrando boa confiabilidade e validade.

Palavras-chave: ataxia cerebelar, escala para avaliação e graduação de ataxia, escala cooperativa internacional para graduação de ataxia.

The cerebellum and its major connection are subject to a number of diseases. One of the most relevant consequences of cerebellar dysfunction is ataxia, a neurological dysfunction of motor coordination, which may affect fundamental activ- ities such as gaze, speech, gait, and balance ${ }^{1}$. The hereditary ataxias comprise a very large spectrum of genetically determined neurodegenerative disorders with progressive ataxia as the prominent symptom $^{2}$. The International Cooperative Atax- 
ia Rating Scale (ICARS) is a scale developed to assess cerebellar ataxia ${ }^{3}$. ICARS was found to be a reliable scale satisfying accepted criteria for interrater reliability, test-retest reliability, and internal consistency. Although validity testing was limited, It was found evidence of validity of ICARS when ataxia disease stages and Barthel index were used as external criteria ${ }^{4,5}$.

In order to measure the severity of cerebellar ataxia in an easier and more practical way, Schmitz-Hubsch et al proposed a new scale: the Scale for the Assessment and Rating of Ataxia (SARA) ${ }^{1}$. This scale was shown to be a reliable and valid measure of ataxia in patients with autosomal dominant spinocerebellar ataxia (SCA) ${ }^{6}$ and in non-SCA patients ${ }^{7}$.

The objective of this study was to translate and validate SARA into Brazilian Portuguese.

\section{METHOD}

\section{Rating scale for ataxia}

SARA has eight items that yield a total score of 0 (no ataxia) to 40 (most severe ataxia); 1 : gait (score 0 to 8 ), 2: stance (score 0 to 6), 3: sitting (score 0 to 4), 4: speech disturbance (score 0 to 6 ), 5 : finger chase (score 0 to 4), 6: nose-finger test (score 0 to 4), 7: fast alternating hand movements (score 0 to 4), 8: heel-shin slide (score 0 to 4). Limb kinetic functions (items 5 to 8 ) are rated independently for both sides, and the arithmetic mean of both sides is included in the SARA total score ${ }^{6}$.

In addition to SARA, we applied the ICARS scale in all subjects. It consists of four compartments: postural and stance disorders (PD-7 items; 34 points), limb ataxia (LA-7 items; 8 points), dysarthria (DS-2 items; 8 points), and oculomotor disorders (OD-3 items; 6 points) ${ }^{3}$.

The study was approved by the ethics committee of the institution. Informed and written consent was obtained from all participants.

\section{Translation of SARA and cultural adaptation}

The translation of SARA was carried out by 2 qualified professionals, whose native language is Brazilian Portuguese, fluent in English and with knowledge on ataxia subject. Additionally, the translator was advised to carry out a semantic translation and not just a literal one, as well as to use words that would cause the same impact in our cultural context.

This process resulted in two forward translations: versions 1 and 2. The translators discussed the translations and the consensus resulted in a reconciled version (version 3). Subsequently, an English translator translated the reconciled version into the English language, resulting in back translation (version 4). Version 3 and 4 were then appraised by the authors, through the comparison with the original text for the correction of discrepancies and creation of a consensus version.

\section{Population}

Clinical, demographic and socioeconomic data were collected prior to the test. A total of 30 individuals of both sexes with ataxia symptoms voluntarily participated in the study. The inclusion criteria were age between 18 and 60 years and specific hereditary ataxia diagnosis on family history.

\section{Statistical analysis}

A descriptive analysis was performed considering the following parameters: gender, onset age, time of disease, etiology of ataxia, first symptom, SARA score and ICARS score using mean \pm standard deviation (SD) for continuous variables with normal distribution, and $\mathrm{n}(\%)$ for nominal variables. For evaluating the reliability of SARA score we used the Cronbach's alpha coefficient. We used the Pearson correlation coefficient for evaluating the correlation between ICARS and SARA scores, and among SARA individual items. Significant values of $r$ were set at $>0.5$, and of $\mathrm{p}$ were set at $<0.05$. The statistical analyses were performed using software Prism 3.0.

\section{RESULTS}

We evaluated thirty patients with progressive ataxia. Table 1 summarizes their demographic and clinical characteristics.

We did not find correlation between SARA and ICARS score in our sample, as illustrated in the figure.

The reliability analysis of the 8-question scale based on Bowling instructions, showed a predominance of statistically positive correlations $(\mathrm{p}<.05)$ in each question, as presented in Table 2.

Cronbach's alpha coefficient for all questions (q) together was 0.94, what represents a good internal consistence.

Table 1. Clinical and demographic data.

\begin{tabular}{lc}
\hline Gender & \\
$\quad$ M:F & $16: 14$ \\
Onset age (years) & $34.4 \pm 12.2$ \\
Time of disease (years) & $10.8 \pm 9.9$ \\
Etiology of ataxia & \\
SCA-3 & $18(60 \%)$ \\
SCA-2 & $4(13.3 \%)$ \\
Friedreich & $2(6.7 \%)$ \\
SCA-6 & $2(6.7 \%)$ \\
Unknown & $4(13.3 \%)$ \\
First symptom & \\
Gait disorder & $25(83.3 \%)$ \\
Falls & $2(6.7 \%)$ \\
Dysarthria & $1(3.3 \%)$ \\
Parkinsonism & $2(6.7 \%)$ \\
ICARS score & $44.7 \pm 21.3$ \\
SARA score & $16.6 \pm 8.3$ \\
\hline
\end{tabular}


Table 2. Matrix of ordinal correlations (Pearson) among scale questions (Q).

\begin{tabular}{ccccccccc}
\hline & Q1 & Q 2 & Q 3 & Q 4 & Q 5 & Q 6 & Q 7 & Q 8 \\
\hline Q 1 & 1 & 0.912194 & 0.606978 & 0.814481 & 0.603999 & 0.582988 & 0.653376 & 0.638723 \\
Q 2 & 0.912194 & 1 & 0.575512 & 0.734618 & 0.69994 & 0.573764 & 0.675112 & 0.645118 \\
Q 3 & 0.606978 & 0.575512 & 1 & 0.70757 & 0.634063 & 0.802191 & 0.525731 & 0.519335 \\
Q 4 & 0.814481 & 0.734618 & 0.70757 & 1 & 0.642731 & 0.679917 & 0.726675 & 0.61475 \\
Q 5 & 0.603999 & 0.69994 & 0.634063 & 0.642731 & 1 & 0.741811 & 0.690145 & 0.66253 \\
Q 6 & 0.582988 & 0.573764 & 0.802191 & 0.679917 & 0.741811 & 1 & 0.695179 & 0.408233 \\
Q 7 & 0.653376 & 0.675112 & 0.525731 & 0.726675 & 0.690145 & 0.695179 & 1 & 0.574415 \\
Q 8 & 0.638723 & 0.645118 & 0.519335 & 0.61475 & 0.66253 & 0.408233 & 0.574415 & 1 \\
\hline
\end{tabular}

Alfa-Cronbach $=0.94 .{ }^{*}$ All correlations present significance $<0.05$.

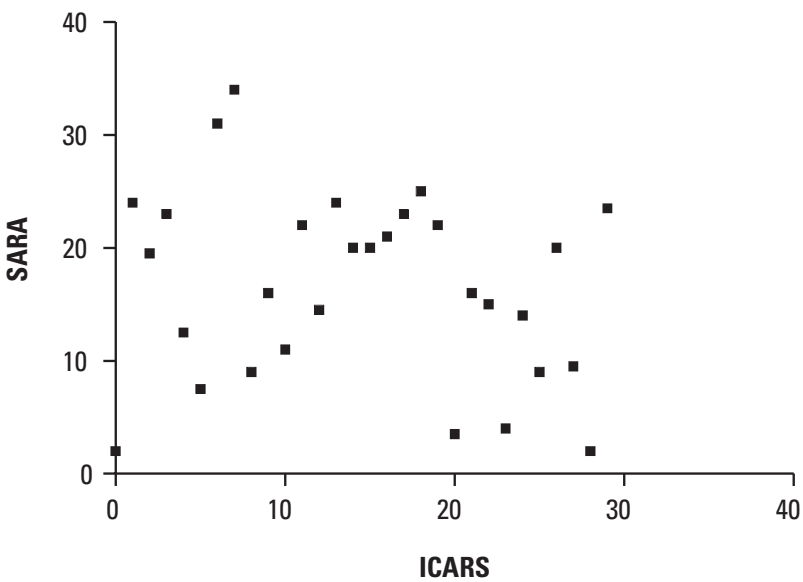

Figure. ICARS and SARA correlation. $r=0.33 ; p=0.07$.

\section{DISCUSSION}

SARA scale was translated to Brazilian Portuguese with adequate internal consistence. We did not need to change words or sentences as the scale was very simple.

In the present study, a significant correlation between ICARS and SARA was not found although a previous study $\mathrm{did}^{8}$. A possible explanation is that the number of patients in our sample is very small to be statically significant in a scale with a larger number of items such as ICARS. The larger number of items in this scale is also related to redundant and overlapping features, making errors more possible. In addition, the use of vague expressions like: "mild, moderate and severe" is reduced in SARA compared to ICARS. This improvement makes the scale more independent to evaluator's subjective judgment ${ }^{8}$. Finally, SARA scale does not evaluate oculomotor functions, which is significantly impaired in some types of spinocerebellar ataxia.

In recent years many disease-specific scales for some types of ataxic disorders have been validated, including Friedreich Ataxia Rating Scale (FARS) for Friedreich ataxia ${ }^{9}$ and the Unified Multiple System Rating Scale (UMSARS $)^{10}$ for multiple system atrophy. Schmahmann et al developed a brief ataxia rating scale (BARS), based on a modified form of the ICARS ${ }^{11}$ and a comparison of three clinical rating scales in Friedreich ataxia (FARS, ICARS and SARA) showed that SARA is applicable and well suited for clinical trials of FRDA ${ }^{12}$.

In the future, an appropriate and validated neurological assessment scale for each type of ataxia may be necessary, but that would allow comparability between studies, because the current ataxia rating scales are cumbersome and not designed for clinical practice ${ }^{13}$.

We conclude that the Brazilian version of SARA scale was translated and validated into Brazilian Portuguese language, showing good reliability and validity.

\section{REFERENCES}

1. Mariotti C, Fancellu R, Di Donato. An overview of the patient with ataxia. J Neurol 2005; 252:511-518.

2. Klockgether T. Hereditary ataxias. In: Jankovic J, Tolosa E (Eds). ParkinsonÅfs disease \& movement disorders. 5th Ed. Philadelphia: Lippicott Wiliiams \& Wilkins, 2007:421-435.

3. Trouillas P, Takayanagi T, Hallett M, et al. International Cooperative Ataxia Rating Scale for pharmacological assessment of the cerebellar syndrome: The Ataxia Neuropharmacology Committee of the World Federation of Neurology. J Neurol Sci 1997;145:205-211.

4. Storey E, Tuck K, Hester R, Hughes A, Churchyard A. Inter-rater reliability of the International Cooperative Ataxia Rating Scale (ICARS). Mov Disord 2004;19: 190-192.

5. Schmitz-Hübsch T, du Montcel ST, Baliko L, et al. Reliability and validity of the International Cooperative Ataxia Rating Scale: a study in 156 spinocerebellar ataxia patients. Mov Disord 2006;21:699-704.

6. Schmitz-Hübsch T, du Montcel ST, Baliko L, et al. Scale for the assessment and rating of ataxia: development of a new clinical scale. Neurology 2006; 66:1717-1720.

7. Weyer A, Abele M, Schmitz-Hubsch T, et al. Reliability and validity of the scale for the assessment and rating of ataxia: a study in 64 ataxia patients. Mov Disord 2007:22:1633-1637.

8. Yabe I, Matsushima M, Soma H, Basri R, Sasaki H. Usefulness of the Scale for Assessment and Rating of Ataxia (SARA). J Neurol Sci 2008;15:164-166.

9. Subramony SH, May W, Lynch D, et al. Measuring Friedreich ataxia: interrater reliability of a neurologic rating scale. Neurology 2005; 64:1261-1262.

10. Wenning GK, Tison F, Seppi K, et al. Development and validation of the Unified Multiple System Atrophy Rating Scale (UMSARS). Mov Disord 2004; 19: 1391-402.

11. Schmahmann JD, Gardner R, Macmore J, Vangel MG. Development of a brief ataxia rating scale (BARS) based on a modified form of the ICARS. Mov Disord 2009; 15:1820-1828

12. Bürk K, Mälzig U, Wolf $\mathrm{S}$, et al. Comparison of three clinical rating scales in Friedreich ataxia (FRDA). Mov Disord 2009; 24:1779-1784

13. Trujillo-Martín M, Serrano-Aguilar P, Monton-Alvarez F, Carrillo-Fumero R. Effectiveness and safety of treatments for degenerative ataxias: a systematic review. Mov Disord 2009: 24: 1111-2114. 